\title{
o Programa Brasileiro de Genética Evolucionária de Populações, de Theodosius Dobzhansky ${ }^{1}$
}

Theodosius Dobzhansky's Brazilian Program

of Evolutionary Population Genetics

Thomas F. Glick*

\section{Resumo}

Nas décadas de 1940 e 1950, a Fundação Rockefeller estabeleceu um programa para o desenvolvimento da genética de populações na Universidade de São Paulo, sob a direção do geneticista norteamericano Theodosius Dobzhansky, nascido na Rússia. O grande sucesso desse programa foi atribuído ao tipo de organização da pesquisa, realizada em grupos, prática introduzida por Dobzhansky. O presente artigo analisa essa conclusão, com base nas reminiscências do geneticista suíço Hans Burla, membro estrangeiro do grupo original de Dobzhansky. Palavras-chave: Theodosius Dobzhansky; Programa Brasileiro de Genética Evolucionária de Populações; Hans Burla.

\section{Abstract}

In the 1940s and 50s the Rockefeller Foundation established a program for the development of population genetics at the Universidade de São Paulo under the direction of the Russian/North American geneticist Theodosius Dobzhansky. The great success of this program was said to have been the result of the kind of research organization, in teams, that Dobzhansky introduced. An evaluation of this conclusion is analyzed, based on the reminiscence of the Swiss geneticist, Hans Burla, a foreign member of the original Dobzhansky group.

Keywords: Theodosius Dobzhansky; Brazilian Program of Evolutionary Population Genetics; Hans Burla.

Nas décadas de 1930 e 1940, Theodosius Dobzhansky modificou substancialmente a natureza da pesquisa em genética evolucionária: ele constatou que "experimentos de campo poderiam ser organizados com a mesma precisão e rigor característicos de experimentos de laboratório" e, com isso, permitiu o desenvolvimento de linhas de pesquisa que romperiam com a tradicional oposição entre biologia de campo e biologia laboratorial. ${ }^{2}$

^ Boston University. Boston - MA 02215 - USA. tglick@bu.edu. 
Dobzhansky nasceu em Nemirov, na Rússia, em 1900. Inspirado pela leitura do livro A origem das espécies, de Darwin, estudou biologia na Universidade de Kiev, concentrando-se no estudo de besouros. Como bem argumentou Nikolai Krementsov, os primeiros trabalhos de Dobzhansky em entomologia prenunciavam sua abordagem posterior da genética populacional. A pesquisa entomológica na Rússia, quando Dobzhansky foi a ela apresentado, não focava espécimes individuais, mas "grupos, séries, massas de espécimes. Em tais circunstâncias, o problema prático e teórico central era distinguir diferentes espécies e, dentro delas, distintas subespécies e variedades". ${ }^{3}$ Além disso, diferentemente da pesquisa entomológica nos Estados Unidos, onde apenas se discutiam espécies no contexto da taxonomia, na Rússia era comum o estudo de espécies com referência a conceitos evolucionários, como fatores afetando a especiação. Como era bastante aceito que a interesterilidade seria um identificador das fronteiras entre espécies, entomólogos russos desenvolveram a idéia do isolamento como fator na especiação. Dobzhansky queria entender quais eram os mecanismos causadores do isolamento. A partir dessas considerações, Krementsov conclui que, na zoologia russa, "eram os entomologistas quem melhor entendia a necessidade de uma interpretação genética do problema das espécies” (Krementsov, 1994, p.37-38, 43).

Em Kiev, Dobzhansky havia dominado as técnicas e abordagens da zoologia experimental e, assim, estava pronto "para ver a importância de questões funcionais e experimentais relacionadas ao processo evolucionário" (Allen, 1994, p.92). Ele reconheceu que espécies não eram agregados homogêneos de indivíduos quase idênticos - isto é, não eram "tipos” - "mas grupos de indivíduos que poderiam ser descritos como tendo considerável variação genética e plasticidade, uma população dentro da qual genes podiam ser trocados".

Em 1924, ele se mudou para Leningrado e foi trabalhar para Yuri Filipchenko, que ali tinha estabelecido um laboratório de estudos sobre Drosophila. Em dezembro de 1927, Dobzhansky chegou aos Estados Unidos, com uma bolsa da Fundação Rockefeller para trabalhar no laboratório de estudos sobre Drosophila, de Thomas Hunt Morgan, na Universidade Columbia. Em seguida mudou-se para o Instituto de Tecnologia da Califórnia, para onde, em 1930, Morgan transferiu seu laboratório. Lá, ele desenvolveu um método para estudar populações naturais de Drosophila, escrevendo sua famosa série de artigos sobre genética populacional experimental. Descobriu que a grande variação genética entre populações selvagens de moscas de fruta lhes permitia adaptar-se a uma enorme diversidade de nichos ecológicos. ${ }^{4}$ 


\section{DOBZHANSKY NO BRASIL}

O ambicioso programa de pesquisa em populações selvagens de Drosophila de Dobzhansky coincidiu com o interesse da Fundação Rockefeller em "investir" na biologia brasileira. O modus operandi da Fundação não era fazer ciência a partir das bases, mas sim identificar cientistas talentosos, investir neles e em seus programas de pesquisa e, assim, "elevar ainda mais os picos" (nas famosas palavras de Wickliffe Rose, diretor do Quadro Internacional de Educação da Fundação Rockefeller). Um funcionário da Fundação em particular, Harry Miller, que ocupa um lugar quase mítico na história das ciências da vida no Brasil e esteve no país em 1941, ficou particularmente impressionado com André Dreyfus (1897-1952) na Universidade de São Paulo (USP).

Dreyfus, formado em medicina, ensinava biologia geral, primeiro no Rio, depois em São Paulo; sua área de pesquisa era a histologia. Na década de 1920, ensinava evolução em seu curso de biologia geral. Quando a USP foi fundada, em 1934, tornou-se o primeiro professor de biologia e passou a ministrar cursos sobre evolução e genética, campo em que era autodidata. Um professor extraordinário - "o melhor que já tive", de acordo com Antonio Brito da Cunha. ${ }^{5}$ Dreyfus era tão brilhante que, em 1942, Miller o convidou para se transferir para os Estados Unidos. Uma das estratégias típicas da Fundação era enviar cientistas promissores para aperfeiçoar sua educação e metodologia em laboratórios de professores que se destacavam em seus campos: jovens sul-americanos geralmente eram enviados aos Estados Unidos. Mas Dreyfus disse a Miller que tinha de dar seus cursos e não poderia deixar São Paulo. Miller, por sua vez, argumentou que um professor americano - Theodosius Dobzhansky - poderia assumir os cursos de Dreyfus na sua ausência. Porém, quando Dobzhansky veio a São Paulo, em 1943, Dreyfus achou desnecessário ir aos Estados Unidos, uma vez que tinha agora o geneticista apropriado à sua disposição.

Dobzhansky veio para uma estada de três meses e ministrou um curso sobre evolução que se tornaria um marco na genética brasileira. As aulas eram dadas no departamento de Química da USP. Cerca de vinte estudantes se matricularam, mas a maioria dos biólogos também assistia às aulas, assim como representantes de outras entidades locais, como o Instituto de Biologia, um grupo que incluía Henrique da Rocha Lima, Clemente Pereira e Zeferino Vaz. Assim, o curso influenciou todos os biólogos de São Paulo. Além disso, de Piracicaba e Campinas vieram Carlos Krug e Friedrich Brieger, respectivamente, cada um trazendo consigo de quinze a vinte de seus estudantes - en- 
tre os quais, Alcides Carvalho. As aulas eram extremamente procuradas; ouvintes traziam suas próprias cadeiras. Dobzhansky escrevia suas aulas em inglês, Dreyfus as traduzia para o português e então Pavan e Brito liam o texto em voz alta para Dobzhansky, para corrigir sua pronúncia. Este registrou cada aula em russo. De acordo com Pavan, esse processo produziu uma espécie de seminário particular para si mesmo e para Brito. Ao final de sua estada, Dobzhansky sabia português e era capaz de falar bem a língua, uma vez que os sons russos são semelhantes aos da língua portuguesa. ${ }^{6}$

Além de suas aulas semanais sobre a evolução, Dobzhansky iniciou um projeto sobre a genética populacional do gênero Drosophila, visando estender seus estudos de populações nativas de ambientes temperados, comparando-as com populações de países tropicais. Dobzhansky e Pavan coletaram e classificaram espécimes de Drosophila, ${ }^{7}$ quando o russo selecionou as espécies interessantes para estudar. Sua idéia era comparar uma espécie de grande população com outra, de pequena população. Ele levou as amostras de volta para Nova York e, seguindo seu método usual, usou cepas preparadas em experimentos com raios X. Pavan foi para Columbia em 1945 e lá ficou por um ano e meio, trabalhando na citogenética da Drosophila nebulosa.

Dobzhansky retornou ao Brasil em junho de 1948 e permaneceu no país até agosto de 1949. A Fundação Rockefeller expandiu a equipe da USP, trazendo Antonio Cordeiro, de Porto Alegre, Chana Malogolowkin e A. G. L. Cavalcanti, do Rio de Janeiro, Hans Burla, de Zurique, e Martha Wedel, de Buenos Aires. Dobzhansky montou dois grupos de trabalho. O primeiro, que incluía Pavan, Dobzhansky, Malogolowkin e Cavalcanti, estudaria a variabilidade genética em duas espécies de Drosophila, D. willistoni e D. prosaltans. Esse estudo mostrou que a freqüência de genes letais em populações nativas é maior em regiões tropicais que em regiões temperadas. O segundo grupo, que incluía Dobzhansky, Brito da Cunha, Burla e Wedel, estudou a variação cromossômica em quatro espécies-irmãs de Drosophila: willistoni, paulistorum, tropicalis e equinoxalis.

O mais importante conjunto de experimentos foi projetado para ilustrar variabilidades genéticas ocultas na forma de polimorfismo cromossômico e para explicar as vantagens adaptativas advindas dessa variabilidade. $\mathrm{O}$ termo "polimorfismo cromossômico" refere-se ao fenômeno de inversão de segmentos de cromossomo. ${ }^{8}$ Eles buscavam explicar o significado da incidência de inversões cromossômicas (34 delas) em willistoni. Essa genética notável estava correlacionada com a diversidade do ambiente. Willistoni, que em uma 
região seca da Bahia tinha uma baixa freqüência de inversões, apresentou freqüência mais alta num ambiente com maior diversidade ecológica.

Alta variabilidade significa a capacidade de explorar mais nichos, especialmente em vista da presença de espécies-irmãs competidoras. O padrão da freqüência de inversões nessas espécies revelou uma seleção darwiniana. Ao estruturar dessa forma o estudo, comparando populações de Drosophila em diferentes situações ecológicas, Dobzhansky de fato inventou a ecologia tropical, como um subproduto da genética populacional tropical.

Dobzhansky só voltaria a viver no Brasil entre junho de 1954 e junho de 1955. Mas, em 1952, a Fundação Rockefeller financiou uma pesquisa de Antonio Salzano e Dranko Brncic (Santiago, Chile) sobre as Drosophila. Com Brito, eles estudaram grupos de duas espécies muito similares, uma bastante difundida e outra, semelhante àquela, porém rara. A variabilidade cromossômica foi estudada. Novamente, eles descobriram que espécies mais difundidas apresentam maior variabilidade cromossômica que espécies mais especializadas.

Brito da Cunha esteve em Columbia entre setembro de 1949 e abril de 1951. Lá, estudou a influência de diferentes alimentos na viabilidade de diferentes tipos cromossômicos em populações de laboratório. Descobriu-se que a freqüência de variabilidade (inversão) variava de acordo com o alimento usado, leveduras e bactérias extraídas de Drosophila na natureza. Brito da Cunha foi para a Universidade da Califórnia, aprender mais sobre leveduras e bactérias. Enquanto isso, Dobzhansky foi para Yosemite. Lá, e no Brasil, eles estudaram a atração de Drosophila por diferentes alimentos. Descobriram que drosófilas escolhem comida pelo cheiro da fermentação. As preferências diferem de uma espécie para outra. Drosófilas podiam escolher diferentes cepas de leveduras mesmo quando análises químicas, à época, não conseguiam detectar diferenças. ${ }^{9}$

\section{BURLA NO BRASIL}

Tendo descrito, em termos gerais, a pesquisa sobre willistoni, seguirei agora o detalhado relato de Hans Burla, como ele registrou numa longa carta de 1992:

Foi uma grande experiência ser membro do grupo de Dobzhansky em São Paulo por um ano. Quando a equipe foi montada, pensava-se que o Dr. Adriano Buzzati Traverso, de Pavia, ${ }^{10}$ faria parte dela. Mais tarde, ele recusaria o convite. Naquela época, eu era doutorando do professor Ernst Hadorn ${ }^{11} \mathrm{em}$ Zurique, e, 
como Hadorn tinha boas relações não só com Dobzhansky mas também com Buzzati, ele sugeriu meu nome como substituto. Apesar de ser capaz de trabalhar duro em campo e no laboratório, no início eu não estava preparado para entender suficientemente a teoria implícita. Trazia comigo uma formação em genética mendeliana, incluindo fisiologia do desenvolvimento, como a ensinava Hadorn, assim como um treinamento auto-imposto em distinções taxonômicas de espécies. Buzzati teria contribuído mais na elaboração dos projetos e na avaliação dos resultados.

Burla se recorda de ter levado o ano inteiro em São Paulo para dominar as suposições teóricas de Dobzhansky.

\section{A PESQUISA SOBRE A ESPÉCIE WILLISTONI}

Nem tudo que fizemos foi perfeito. Uma de nossas realizações foi mostrar que, no Brasil, o polimorfismo cromossômico em $D$. willistoni variava espacialmente. O padrão observado de variação sugeriu que o mero número de hélices invertidas de uma amostra tinha uma correlação positiva com a riqueza da vegetação local. Embora eu ainda pense que a conclusão a que chegamos seja verdadeira, até hoje há pouca evidência, parcialmente por causa de uma deficiência metodológica. É errado distinguir hélices individuais e contá-las, como fizemos. Uma hélice mostra quando arranjos desiguais de genes são emparelhados em células somáticas. Mas é difícil dizer, a partir de uma hélice, exatamente quais arranjos de genes estão envolvidos. Além disso, em alguns casos, mais de um par de arranjos de genes vão produzir a mesma hélice. Nós deveríamos ter nos esforçado para identificar cada arranjo de genes sem erro.

Burla comenta que o que Dobzhansky fez nos Estados Unidos com $D$. pseudoobscura foi feito na Europa, sob a influência de Dieter Sperlich, com D. subobscura.

As relações observadas entre a feição do polimorfismo de inversões e a diversidade do ambiente pediam uma explicação causal aceitável. As primeiras explicações eram conjecturais, embora aceitáveis como uma teoria a partir da qual hipóteses podem ser derivadas e objetivamente testadas. A procura por uma interpretação mecânica subsiste e é feita com outras espécies de Drosophila em outros países. O que os resultados com $D$. willistoni ressaltaram foi a necessidade 
de maior investigação, pois o assunto já não era novo. Mesmo hoje os problemas ainda não foram resolvidos. Apenas em 1979 foram obtidas, por Dobzhansky, Powell, Taylor e Anderegg, fortes evidências de que a escolha de hábitat explica a variação cariotípica em D. pseudoobscura (American Naturalist, v.114, p.325334). A questão ainda é controversa em $D$. subobscura. O próximo passo deve ser fixar os genes que determinam a resposta ecológica de um cariótipo a condições relevantes do ambiente e entender como a resposta influencia sua adaptação.

Burla especulou que a exigência de identificar todo o arranjo de genes pode ter desencorajado uma repetição do estudo. Em todo caso,

Eu acho que a habilidade de Dobzhansky em trabalhar rápido o levou a escolher atalhos que, mais tarde, poderiam ser considerados impróprios. Apressou-se em tirar conclusões tãologo houvesse examinado algo de perto, mas só sabia realmente qual evidência queria no momento. Isso mostra o nível em que eu contribuí. Apesar de eu ter liberdade para participar das discussões no laboratório, não estava envolvido na definição de metas e abordagens. Eu fui útil (e indispensável) apenas no cumprimento de tarefas específicas, de alguma forma no nível da assistência técnica ... Desde o início, estive mais envolvido apenas nos bastidores ecológicos.

Burla diz que esse insight veio mais tarde. Quando estava trabalhando com Dobzhansky, ele realmente não tinha consciência de nenhuma falha: "Seu conhecimento e sua conduta tornavam fácil concordar com ele. Chegava a ser arriscado ter uma opinião diferente":

A pesquisa sobre willistoni foi uma empreitada promissora, que abriu um novo campo de estudo no Brasil (foi o que me disseram) e produziu alguns bons artigos. Foi planejada por Dobzhansky e feita durante sua estada. Durou enquanto ele esteve envolvido pessoalmente ou incentivando-a de longe. Para preservá-la, ele deveria ter ficado no Brasil por alguns anos, ou outro cientista da sua estatura deveria ter sido indicado. O pequeno grupo poderia, então, ter continuado, e teria crescido. Da forma como foi conduzido, o projeto não passou de um episódio efêmero. Apesar de terem recebido grande apoio e aprendido muito, os poucos membros ativos da equipe de jovens, todos eles, mais cedo ou mais tarde passaram para outros campos de estudo da biologia. Assim, o impacto imediato de Dobzhansky se dissipou ... Freqüentemente, parecia-me que nós não estávamos suficientemente integrados. Em minha opinião, éramos considerados uma 
curiosidade e tivemos pouco efeito na ciência. Colegas de outras universidades nos olhavam com uma indulgência benevolente.

A abordagem coletiva à pesquisa, com um grupo de estudantes trabalhando numa linha particular de pesquisa sob a direção de Dobzhansky, foi uma das marcas distintivas de seu trabalho no Brasil. Como Pavan descreveu ao concorrer a uma bolsa, em 1954,

Nós acreditamos que esse tipo de trabalho traz resultados consideravelmente melhores do que os que podem ser obtidos de uma série de esforços independentes e descoordenados em vários trabalhos isolados de investigação. Afora a massa de dados obtidos, o trabalho resultou na formulação de algumas generalizações significativas para o interesse geral da biologia, embora tímida na época. Como freqüentemente acontece na pesquisa científica, a solução de alguns problemas possibilita o surgimento de novos. Estamos ansiosos para explorar as possibilidades abertas pelos resultados obtidos até agora e para desenvolver mais trabalhos. ${ }^{12}$

Apesar de Burla ter concluído que "não estávamos suficientemente integrados”, uma opinião aparentemente divergente da de Pavan, ele também sentiu que o estilo coletivo havia sido, ao mesmo tempo, importante, distintivo e difícil de reproduzir. Sua visão, em 1949, mostrava que

era uma experiência de trabalho em grupo que, mais tarde, eu mesmo nunca fui capaz de organizar com meus alunos e minha equipe. Significava um esforço conjunto para testar hipóteses, que foi bem-sucedido, na medida em que atingiu as expectativas. Ela me ensinou a me concentrar num projeto, a trabalhar duro e rápido e a relatar sem atraso.

Resumindo sua experiência numa carta a Miller em 1949, Burla afirma:

É muito mais difícil para mim ter uma idéia clara dos efeitos de seu auxílio para a genética no Brasil. Ambos, Pavan e Brito da Cunha, são bons e confiáveis pesquisadores. Cavalcanti e Cordeiro construíram seus laboratórios; os sucessos das atividades de cada um ficam para o futuro, como no meu caso. A luta contra a burocracia brasileira e a necessidade de tomar conta das relações pessoais são mais uma perturbação para o desenvolvimento de um trabalho eficiente, como você certamente sabe muito melhor do que eu. Mesmo assim eu penso que a maioria das condições é agora favorável no Brasil. Os trabalhadores têm seus programas, eles viram o exemplo de como se comportar, possuem excelente 
equipamento óptico para o trabalho de pesquisa, laboratórios com salas climatizadas (em São Paulo) e com salários para auxiliares, que são mais altos que em muitos países da Europa. ${ }^{13}$

Quando se compara essa afirmação tardia de Burla com as de Pavan na década de 1950, é interessante observar que Pavan enfatiza a organização igualitária da pesquisa, mas Burla mais tarde reconheceu que havia também uma hierarquia, com Dobzhansky no topo.

Burla se mudou para o Rio de Janeiro:

Eu fiquei com Cavalcanti no Rio dois anos e meio, entre 1952 e 1954. Cavalcanti dava aulas, mas raramente era visto no laboratório. Quando cheguei, estava preparado para me juntar a um grupo de genética populacional. Inicialmente, Cavalcanti parecia trabalhar num projeto do qual me contou pouco. Quando eu descobri que estava sozinho, me senti incapaz de começar ... Foi nessas condições que comecei a estudar a taxonomia de Drosophila.

Ele tinha a intenção de permanecer no Brasil, mas a inflação reduzia o valor de sua bolsa, por isso aceitou uma oferta para se juntar à equipe de Hadorn, em 1954.

Por mais agradáveis que sejam os estudos populacionais, ainda estou convencido de que estudos taxonômicos com drosófilas no Brasil são indispensáveis por várias razões. Até Dobzhansky havia feito um esforço desse tipo com Pavan em 1943, para preparar o campo para projetos em genética. Em 1948/1849, fomos várias vezes confrontados com problemas taxonômicos não resolvidos. Há considerações ecológicas em que o número e o tipo de espécies coexistentes são importantes. Antes que possam ser contadas, elas precisam ser conhecidas.

Apesar de nunca ter perdido o interesse em polimorfismo de inversões, Burla não mais trabalhou com willistoni. Trabalhou, sim, com D. subobscura, uma espécie quase tão polimórfica quanto $D$. willistoni e que apresentava os mesmos problemas básicos.

\section{Conclusão}

A importância da pesquisa sobre willistoni, medida pelo número de publicações e por sua longa vida de citações (Glick, 2003, p.155, para números 
retirados do Science Citation Index),${ }^{14}$ juntamente com a organização eficiente do grupo de pesquisa, são responsáveis pelo sucesso do projeto. O estilo coletivo descrito por Pavan e, numa forma mais nuançada, por Burla, foi o tipo certo de organização social de pesquisa para iniciar uma nova subdisciplina da Biologia no Brasil.

\section{NOTAS}

${ }^{1}$ Tradução de Manuel Amaral Bueno.

${ }^{2}$ ALLEN, Garland. Theodosius Dobzhansky, the Morgan Lab, and the Breakdown of the Naturalist/ Experimentalist Dichotomy, 1927-1947. In: ADAMS, Mark B. (Ed.). The evolution of Theodosius Dobzhansky. Princeton: Princeton University Press, 1994. p.87-98.

${ }^{3}$ KREMENTSOV, Nikolai L. Dobzhansky and Russian Entomology: the origin of his ideas on species and speciation. In: ADAMS, 1994, p.31-48.

${ }^{4}$ LEWONTIN, Richard et al. (Ed.). Dobzhansky's genetics of natural populations I-XLIII. New York: Columbia University Press, 1981.

${ }^{5}$ BRITO DA CUNHA, A. Entrevista. São Paulo, 22 mar. 1990; ver também sua curta biografia de Dreyfus em Revista IEA-USP, São Paulo, n.22, dez. 1994. Disponível em: paginas. terra.com.br/educacao/fdg/artigo_dreyfus.html.

${ }^{6}$ BRITO DA CUNHA. Entrevista; PAVAN, Crodowaldo. Entrevista. São Paulo, 18 ago. 1992.

${ }^{7}$ DOBZHANSKY, Theodosius; PAVAN, Crodowaldo. Studies on Brazilian Species of Drosophila. Boletim da Faculdade de Filosofia, Ciências e Letras da Universidade de São Paulo. Biologia Geral, v.4, p.7-72, 1943. Pavan e Dobzhansky continuaram a coletar espécies brasileiras em 1948. Ver DOBZHANSKY, T. The roving naturalist. Philadelphia: The American Philosophical Society, 1980.

${ }^{8}$ Por inversão, compreende-se um tipo de mutação na qual a ordem dos genes de uma seção do cromossomo é revertida.

${ }^{9}$ DOBZHANSKY, T.; BRITO DA CUNHA, Antonio. Differentiation of nutritional preferences in Brazilian species of Drosophila. Ecology, v.36, p.34-39, 1955.

${ }^{10}$ Buzzati-Traverso (1913-1983), que havia conhecido Dobzhansky no laboratório de Morgan em 1935, estabeleceu um laboratório para o estudo de Drosophila em Pavia em 1938.

${ }^{11}$ Hadorn (1902-1976), geneticista do desenvolvimento (developmental geneticist), que estudou fatores letais em Drosophila.

${ }^{12}$ PAVAN, Crodowaldo. Research Project of Study of Population Genetics and Ecology of Tropical Organisms, Rockefeller Archive Center, Rockefeller Foundation Archives, Record Group 1.2, Série 305, Caixa 45, Folder 390. Original em inglês. Citado em GLICK, Thomas F. A Fundação Rockefeller e a emergência da Genética no Brasil (1943-1960), In: 
DOMINGUES, Heloisa; SÁ, Magali Romero; GLICK, Thomas F. (Ed.). A recepção do Darwinismo no Brasil. Rio de Janeiro: Ed. Fiocruz, 2003. p.145-163. p.158.

${ }^{13}$ Burla para Miller, 1 dez. 1949, Rockefeller Archive Center, Rockefeller Foundation Archives, Record Group 1.2, Série 305, Caixa 45, Folder 390. Original em inglês.

${ }^{14}$ Os dois artigos mais citados foram BRITO DA CUNHA, Antonio; BURLA, Hans; DOBZHANSKY, Theodosius. Adaptive Chromosomal Polymorphism in Drosophila willistoni. Evolution, v.4, p.212-235, 1950; BRITO DA CUNHA, Antonio; DOBZHANSKY, Theodosius. A further study of chromosomal polymorphism in Drosophila willistoni, and its relation to the environment. Evolution, v.8, p.119-134, 1954.

Artigo recebido em setembro de 2008. Aprovado em setembro de 2008. 